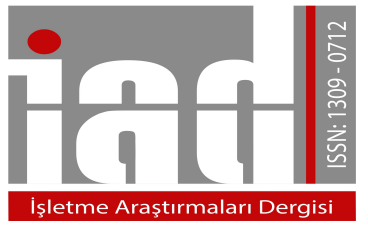

Journal Of

Business Research

Turk

www.isarder.org

\title{
Otomobil Satışları ve Otomotiv Sektörü Hisse Senedi Fiyatları Arasındaki İlişkinin Granger Nedensellik Testi İle Analizi: Borsa İstanbul Örneği
}

\author{
The Analysis Of The Relationship Between The Automobile Sales And \\ Automotive Industry Stock Prices By Granger Causality Test: Istanbul \\ Stock Exchange Case
}

\author{
Zafer ŞAHIN \\ Dumlupınar Üniversitesi \\ Sosyal Bilimler Enstitüsü \\ Yüksek Lisans Öğrencisi \\ Kütahya, Türkiye \\ orcid.org/0000-0002-2765-3138 \\ zafer.sahin111@gmail.com
}

\author{
Cumhur ŞAHIN \\ Bilecik Şeyh Edebali \\ Üniversitesi, Bozüyük Meslek \\ Yüksekokulu \\ Bozüyük, Bilecik, Türkiye \\ orcid.org/0000-0002-8790-5851 \\ cumhur.sahin@bilecik.edu.tr
}

\begin{abstract}
Özet
Otomotiv sektörü, sürekli olarak gelişen ve ekonomiye önemli katkılar sağlayan gelișmiș sektörlerden biridir. Otomotiv sektöründeki gelișmeler, ülke ekonomisinin büyümesinde önemli olabilmektedir. Araştırmada otomotiv sektörüne yönelik verilerin seçiminde ticari olmayan müşterilerin talepleri ve buna bağlı olarak hisse senedi değerlerine yönelik bir araştırma yürütülmesi planlanmıştır. Bu kapsamda Türkiye'de toplam otomobil satış miktarı ve seçili bazı hisse senedi fiyatları arasındaki ilişki incelemeye alınmıştır. Araştırmada Doğuş Otomotiv hisse senedi yıllık ortalama fiyatı, Tofaş hisse senedi yıllık ortalama fiyatı, Ford Otosan hisse senedi y1llık ortalama fiyatı ve Türkiye'de toplam sıfır araba satış sayısı arasındaki ilişki araştırılmıştır. Araştırma kapsamında Granger Nedensellik testi ile değişkenler arasındaki ilişkiler incelenmiştir. Araştırma sonucunda Türkiye'de toplam sıfır araba satış sayısı ile hisse senetleri fiyatları arasında istatistiksel olarak anlamlı bir farklılığa rastlanmamıştır.
\end{abstract}

Anahtar Kelimeler: Otomotiv sektörü, Hisse senedi, Granger Nedensellik testi

\begin{abstract}
The automotive sector is one of the developed sectors that has been continuously developing and making significant contributions to the economy. Developments in the automotive sector may be important in the growth of the country's economy. In the research, it was planned to carry out a research on the demand of non-commercial customers and the related stock values in the selection of data for the automotive sector. In this context, the amount of total car sales in Turkey, has been studied and selected
\end{abstract}


some relationship between stock prices. Doğuş Otomotiv annual average stock price in the study, the average annual stock price Tofas, Ford Otosan relationship between the stock price and the average annual total number of new cars sold in Turkey were investigated. In the context of the research, the relationships between the variables and the Granger causality test are examined. shares with a total number of new cars sold in Turkey as a result of the study did not find a statistically significant difference between the price.

\section{Keywords: Automotive Industry, Stocks, Granger Causality Test}

\section{GíRiş}

Otomotiv sektörü genel itibariyle karayolu taşıt araçlarının üretimini ve taşıtların üretimi için gerekli olan parçaların üretimini gerçekleştiren sektördür. Otomotiv sektörü tüm dünya ülkeleri için en önemli sektörlerden biri olarak görülmekle beraber özellikle sanayileşmiş ülkelerin lokomotifi konumundadır. Otomotiv sektörünün lokomotif bir sektör olmasının nedeni diğer birçok sektörle ilişkili durumda olmasından kaynaklanmaktadır (Verstrepen vd., 1999; Yurdakul, 2003; Görener, 2008; İnançlı ve Konak, 2014). Otomotiv sektörü petro-kimya, demir, çelik ve lastik sektörü gibi birçok sektörle yakından ilişkilidir. Otomotiv sektörü bu sektörlerde alıcı konumundadır ve bu nedenle bu sektörlerin gelişim göstermesinde otomotiv sektörünün büyüklüğü önem kazanmaktadır. Otomotiv sektörü satıcı konumunda da turizm, tarım, inşaat ve ulaştırma gibi sektörlerle yakından ilişkilidir. Bu nedenle otomotiv sektöründe meydana gelebilecek değişimler, diğer sektörleri de etkileyebilmektedir (Laux, 1992 Zapata ve Nieuwenhuis, 2010; Sturgeon ve Van Biesebroeck, 2010).

Tüm sektörlerde olduğu gibi otomotiv sektörü de reel sektörde etkin olduğu kadar sermaye piyasasında da önemli bir yer edinmektedir. Bununla beraber reel sektör ile sermaye sektörünün tam olarak birbirleriyle ilişkili olmadıkları açıktır. Bu araştırmada otomotiv sektörü için reel piyasa verileri ve sermaye piyasası verileri arasında karşılaştırma yapılacak ve sıfır otomobil satışları ile otomotiv firmaları hisse senedi getirileri arasında bir ilişki olup olmadığ incelendiğinde, otomotiv sektörü hisse senedi fiyatları ile enflasyon, faiz oranı, döviz kuru ve özellikle ham petrol fiyatları gibi makroekonomik değişkenler arasındaki ilişkiyi ele alan birçok çalışma olduğu, buna karşın, otomobil satışları ile otomotiv sektörü hisse senedi fiyatları arasındaki ilişkiyi ele alan çalışmaların sınırlı oluşu dikkat çekicidir. Üstelik var olan çalışmaların hepsi de yurt dışı kaynaklı olup, ülkemizde bu konuyla ilgili hiçbir çalışmanın olmadığı görülmüş, araştırmanın konusu bu nedenle seçilmiştir. Dolayısıyla bu çalışmanın, literatürdeki eksikliğe bir katkısının olacağı düşünülmektedir.

\subsection{Otomotiv Sektörü Tanımı}

Otomotiv sanayi, karayollarında belli standartlara ve mevzuata uygun olarak üretiminin gerçekleştirildiği, motorlu taşıtlar sanayisidir (Karbuz vd., 2009). Otomotiv sanayii, taşıt aracı üreticileri, taşı aracı üreticilerine montaj ve yedek parça tedarik eden üreticileri, üretilen araçlarla ilgili bakım ve servis istasyonları hizmetlerini ve araçların satış hizmetlerini kapsayan oldukça geniş bir sektördür (Sturgeon ve Van Biesebroeck, 2011; Aktaş ve Akkurt, 2015).

Otomotiv sektörü, küresel anlamda sürekli olarak gelişen ve rekabetin yoğun olarak yaşandığı sektörlerden biridir. Sektörün sürekli olarak gelişmesi ve rekabet ortamının artması, yeni markaların sektöre girmesine engel olmaktadır. Otomotiv sektörü özellikle büyük şirketlerin küresel boyutlarda üretim ve satış gerçekleştirdikleri 
bir sektördür. Türkiye'de otomotiv sektörü bu büyük şirketlerin uzantıları şeklinde piyasada yer almaktadırlar.

\subsection{Dünyada Otomotiv Sektörü}

Dünyada otomotiv sektörü özellikle Avrupa'da Almanya ve Fransa önderliğinde doğmuş ve 1900'lü yıllarda sanayileşmenin hız kazanmasıyla beraber diğer ülkelere hızlı şekilde yayılmıştır. 1908 yılı itibariyle Henry Ford tarafindan kurulan "Ford Motor Company" şirketi tarafindan montaj hattı kurularak "Model T" adı altında otomobillerin üretiminde toplu üretime geçilmiştir (Kaymak, 2009). Otomotiv sektöründe seri üretime ilk olarak ABD'de geçilmiş ve Avrupa'da da takip edilmiştir. Her ne kadar İkinci Dünya Savaşı nedeniyle otomobil üretimine duraksama yaşanmış olsa da, savaş sonrasında Avrupa'da otomobil üretimi yeniden artmıştır (Çalışkan, 2009). 1960'lı yıllarda Japonya'da otomotiv sektöründeki üretim hız kazanmış ve Japonya otomotiv ihracatında önemli bir yere gelmiştir (Görener, 2008). 1987 yılı itibariyle 16 milyon birimlik üretime sahip olup Japonya için "Japon Mucizesi” ismi verilmiştir. Bu ismin verilmesinin nedeni doğal kaynakları açısından zengin olmayan ve ABD’ye göre oldukça küçük olan bir ülkede insan azmi sonucunda yüksek miktarda üretim yapılmasıdır (Aksakal, 2016).

Dünya otomotiv sektöründeki yatırımlar Avrupa ülkeleri ve ABD ile başlamış 1990'lı yıllarla beraber Doğu Avrupa ve sonrasında Asya bölgelerine yatırımlar artmıştır. 1990 yılı itibariyle Güney Kore'de hükümetin de desteğiyle beraber otomotiv sektörüne olan yatırımlar büyük ölçüde artmış ve 1996 yılı itibariyle 2.2 milyon adede ulaşılmıştır (Karabulut,2002).Otomotiv sektöründeki büyüme 1990'lı y1llarda hız kazanmış olmakla beraber 1998 Asya Krizi nedeniyle otomobil üretim kapasitesi azalmıştır. 2000'li y1llarda yeniden kendisini toparlamaya başlayan otomotiv sektörü 2008 küresel kriziyle beraber yine önemli düzeyde yavaşlamaya girmiştir.

Aşağıdaki şekilde dünyada yıllar itibariyle binek otomobil satış rakamları yer almaktadır.

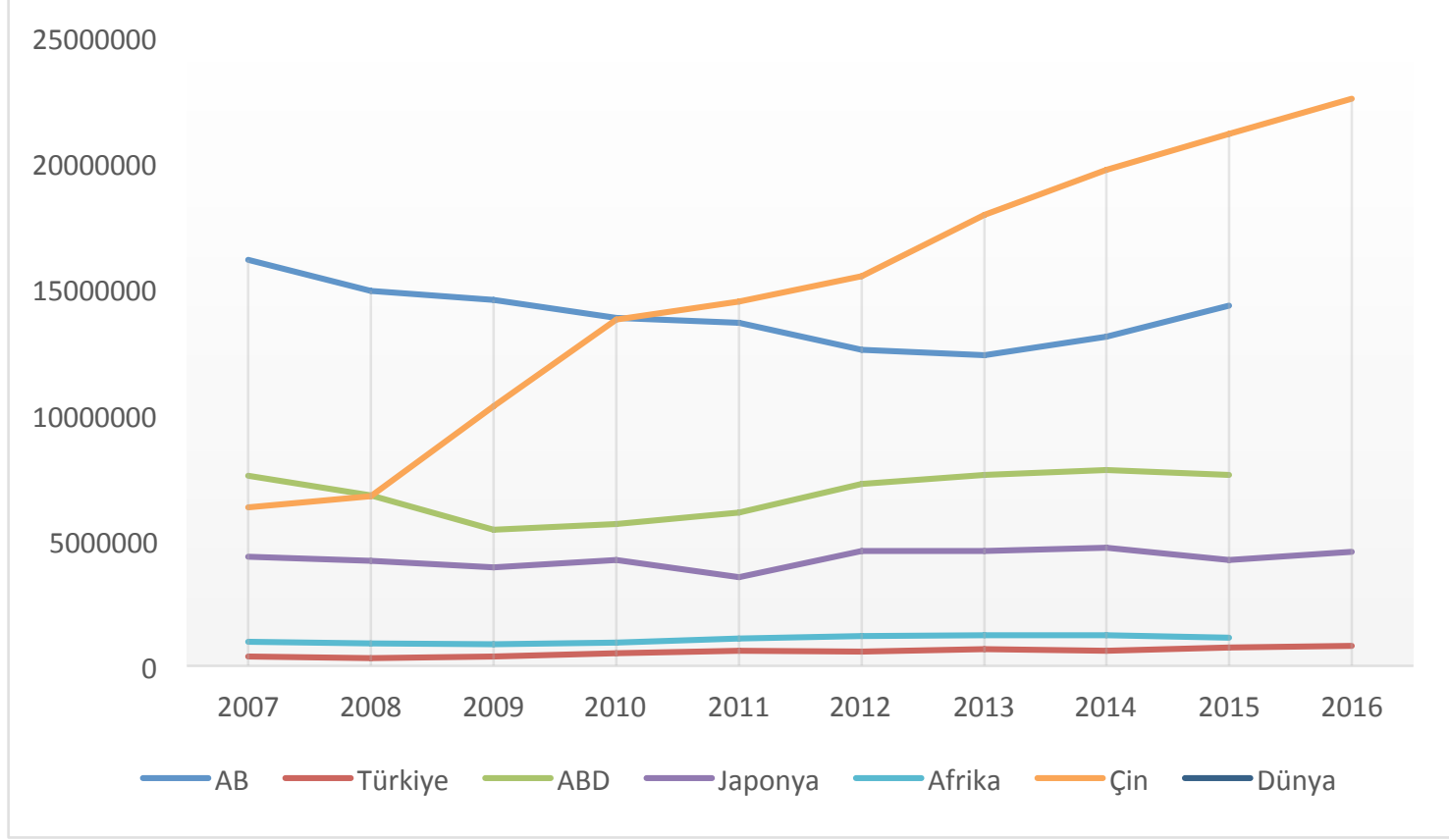

Şekil 1. 2007-2016 Y1lları Binek Otomobil Sayıları

Kaynak: OICA, http://www.oica.net/category/production-statistics/ 


\subsection{Türkiye'de Otomotiv Sektörü}

Türkiye'de otomotiv sanayiye yapılan ilk yatırım 1929 yılında yapılmıştır. 1929 yılı itibariyle İstanbul'da ilk montaj fabrikası kurulmuştur. 1940'lı yıllara gelindiğinde ise otomotiv sektörüne olan yatırımlar artmaya başlamıştır. 1950'li yıllarda traktör ve kamyon montajına başlanmıştır. 1961 yılı itibariyle tamamı Türkiye'de yerli üretim olarak gerçekleştirilen Devrim Otomobili sayesinde ülkeye birçok yabancı yatırımcının gelmesi sağlanmıştır. (Aktaş ve Akkurt, 2015). 1980'li yıllardan sonra yabancı sermayenin yoğun olarak ülkeye girmesi, otomotiv sektöründe modern teknolojileri beraberinde getirmiş ve otomotiv sektörü ihracat odaklı bir yapı kazanmıştır.

Türkiye'de yıllar itibariyle otomotiv sektöründe kurulan firmalar ile ilgili bilgiler aşağıdaki tabloda yer almaktadır.

Tablo 1. Türkiye Otomotiv Sektörü Tarihi

\begin{tabular}{|c|c|c|c|}
\hline Firmalar & Üretim Yeri & $\begin{array}{l}\text { Üretime } \\
\text { Başlama } \\
\text { Tarihi }\end{array}$ & Lisans \\
\hline A.I.O.S. & KOCAELİ & 1966 & ISUZU \\
\hline FORD OTOSAN & $\begin{array}{l}\text { ESKISSEHİR } \\
\text { KOCAELI }\end{array}$ & $\begin{array}{l}1983 \\
2001\end{array}$ & FORD \\
\hline $\begin{array}{l}\text { HATTAT } \\
\text { TRAKTÖR }\end{array}$ & TEKİRDAĞ & 2002 & VALTRA, HATTAT \\
\hline HONDA TÜRKİYE & KOCAELİ & 1997 & $\begin{array}{l}\text { HONDA MOTOR EUROPE. } \\
\text { LTD }\end{array}$ \\
\hline HYUNDAI ASSAN & KOCAELİ & 1997 & HYUNDAI MOTOR COMP. \\
\hline KARSAN & BURSA & 1996 & $\begin{array}{c}\text { HYUNDAI MOTOR } \\
\text { COMPANY BREDA } \\
\text { MENARINI BUS }\end{array}$ \\
\hline M.A.N. TÜRKIIYE & ANKARA & 1966 & MAN TRUCK \& BUS AG \\
\hline M.BENZ TÜRK & $\begin{array}{l}\text { İSTANBUL } \\
\text { AKSARAY }\end{array}$ & $\begin{array}{l}1968 \\
1985\end{array}$ & MERCEDES BENZ \\
\hline OTOKAR & SAKARYA & 1963 & LAND ROVER / FRUEHAUF \\
\hline O. RENAULT & BURSA & 1971 & RENAULT \\
\hline TEMSA GLOBAL & ADANA & 1987 & TEMSA \\
\hline TOFAŞ & BURSA & 1971 & FIAT \\
\hline TOYOTA & SAKARYA & 1994 & TOYOTA \\
\hline T. TRAKTÖR & ANKARA & 1954 & \\
\hline
\end{tabular}

1980 yılı itibariyle Türkiye dış politikasının dışa açık bir duruma gelmesi, otomotiv sektörünün de hızlı şekilde gelişimini desteklemiştir. Aşağıdaki şekilde yıllar itibariyle Türkiye otomotiv sektöründe üretin araç sayıları yer almaktadır. 


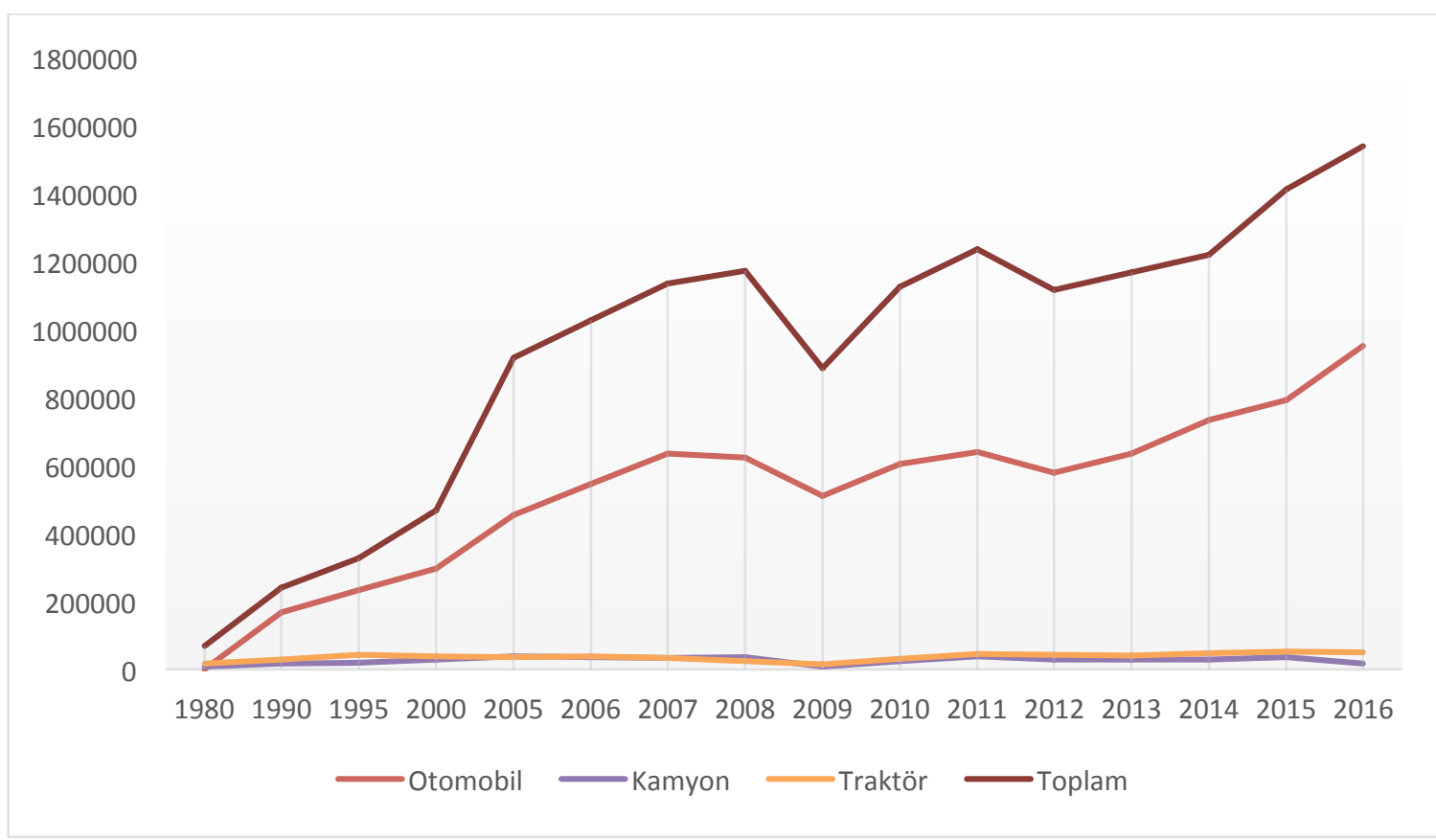

Şekil 2. Türkiye'de otomotiv Sektörünün Üretimi

Kaynak: OSD (2017). Otomotiv Sanayii Genel ve İstatistik Bülteni http://www.osd.org.tr/sites/1/upload/files/Yillik_2017-2224.pdf

Türkiye'de otomotiv sektörünün üretim miktarları incelendiğinde özellikle otomobil üretiminin oldukça yüksek olduğu görülmektedir. Otomobil üretimine göre diğer üretimlerin payının düşük seviyede olduğunu söylemek mümkündür. Bu durum Türkiye'de otomotiv sektörünün en önemli ürününün otomobil olduğunu göstermektedir.

\section{LITERATÜR TARAMASI}

Literatür incelendiğinde, otomotiv sektörü hisse senedi fiyatları ile enflasyon, faiz oranı, döviz kuru ve özellikle ham petrol fiyatları gibi makroekonomik değişkenler arasındaki ilişkiyi ele alan birçok çalışma olduğu, buna karşın, otomobil satışları ile otomotiv sektörü hisse senedi fiyatları arasındaki ilişkiyi ele alan çalışmaların sınırlı oluşu dikkat çekicidir. Bu alanda çok sınırlı çalışma mevcut olup en belli başlıları aşağıdadır:

Edwards ve Stansell'in (1983), yeni araba satışları ile otomobil şirketleri hisse senedi hisse fiyatları arasındaki nedensellik ilişkisini araştırdıkları çalışmada, dört büyük Amerikan otomotiv şirketi için Granger nedensellik araştırması kullanılmış olup, verilerin analizi neticesinde yeni araba satışlarının etkin piyasalar hipotezini doğrular şekilde, hisse senedi fiyatlarına derhal yansıdığı ve aralarında anlamlı ve pozitif bir nedensellik ilişkisi olduğu görülmüştür.

Hoffer ve Reilly'nin (1984), otomobil sektöründe ürün stil değişiminin hisse senedi ile ilişkisini araştıran çalışmalarında, yeni stile sahip otomobillerin satışı ile hisse senedi getirileri arasında anlamlı bir ilişkinin olduğu bulgusuna ulaşılmıştır.

Kleinschmidt ve Cooper (1991), otomotiv sektöründeki ürün yenilikçiliği ile hisse senedi getirilerini inceledikleri çalışmalarında, yenilikçi ürün satışlarının otomotiv sektörü hisse senedi getirilerini olumlu yönde etkilediğini gözlemlemişlerdir. 
Ittner ve Larcker'in (1997), otomobil ve bilgisayar endüstrilerinde ABD, Kanada, Japonya ve Almanya pazarları için yeni ürün satışı ile bu malların hisse senedi fiyatları arasındaki ilişkiyi ele alan çalışmalarında yeni üretim ile hisse senedi getirileri arasında anlamlı bir ilişki saptanmıştır.

Pauwels ve diğerlerinin (2004), otomobil endüstrisindeki yeni üretim ve promosyon teşviklerinin firma değeri üzerindeki etkisini araştırdıkları çalışmada, çok değişkenli zaman serisi modelleri kullanılmış olup, uzun dönemde yeni üretimin firma değeri ve hisse senedi getirisi üzerinde anlamlı ve pozitif yönde bir etkisi olduğu, buna karşın promosyon teşviklerinin firma değeri ve hisse senedi getirisi üzerinde bir etkisi olmadığ

\section{YÖNTEM}

\subsection{Veri Seti}

Araştırmada otomotiv sektörüne yönelik verilerin seçiminde ticari olmayan müşterilerin talepleri ve buna bağlı olarak hisse senedi değerlerine yönelik bir araştırma yürütülmesi planlanmıştır. Bu kapsamda Türkiye'de toplam otomobil satış miktarı ve seçili bazı hisse senedi fiyatları arasındaki ilişsi incelemeye alınmıştır.

Araştırmada kullanılan veri seti şu şekildedir:

- DOAS: Doğuş Otomotiv hisse senedi yıllık ortalama fiyatı (2008-2017)

- TOASA: Tofaş hisse senedi yıllık ortalama fiyatı (2008-2017)

- FROTO: Ford Otosan hisse senedi yıllık ortalama fiyatı (2008-2017)

- SATIS: Türkiye'de toplam sıfır araba satış sayısı (2008-2017)

Hisse senedi fiyatları BIST resmi web sitesinden ve Türkiye'de toplam sıfır araba satış sayısı OICA sitesinden alınmıştır. Veriler analize dahil edilirken logaritmaları alınmıştır.

Tablo 1. Veri Seti

\begin{tabular}{lllll}
\hline & SATIS & DOAS & TOASO & FROTO \\
\hline $\mathbf{2 0 0 8}$ & 494023 & 1.1 & 1.97 & 4.5 \\
\hline $\mathbf{2 0 0 9}$ & 557128 & 1.32 & 1.82 & 3.72 \\
\hline $\mathbf{2 0 1 0}$ & 760913 & 2.52 & 4.12 & 7.6 \\
\hline $\mathbf{2 0 1 1}$ & 864439 & 2.96 & 4.91 & 9.53 \\
\hline $\mathbf{2 0 1 2}$ & 777761 & 4.6 & 6.8 & 13.67 \\
\hline $\mathbf{2 0 1 3}$ & 853378 & 6.8 & 9.84 & 21.67 \\
\hline $\mathbf{2 0 1 4}$ & 767681 & 7.2 & 11.44 & 22.27 \\
\hline $\mathbf{2 0 1 6}$ & 968017 & 10.9 & 15.78 & 28.88 \\
\hline $\mathbf{2 0 1 7}$ & 983720 & 9.88 & 21.53 & 30.33 \\
\hline
\end{tabular}

\subsection{Metodoloji}

\subsubsection{Birim Kök Testi}

Zaman serilerinde birim kökün varlığı serinin durağan olmayan bir yapıya sahip olmasına neden olmaktadır. Zaman serileri için ifade edilen durağanlık kavramı, zaman içinde varyansın ve ortalamanın sabit olması ve gecikmeli iki zaman periyodundaki değişkenlerin kovaryansının değişkenler arasındaki gecikmeye bağlı olup zamana bağlı olmamasidır (Gujarati, 2004). 
ADF Testi;

$H_{0}: \delta=0$ birim köke sahiptir

$H_{1}: \delta<0$ birim köke sahip değildir

Ho hipotezi reddedilirseserinin orijinal seviyesinde durağan olduğu, Ho hipotezi reddedilemiyorsa serinin durağan olmadığı sonucuna ulaşılır. Orijinal seviyesinde durağan olmayan bir serinin durağanlığı sağlanıncaya kadar devresel farkları alınır.

PP Testi;

$H_{0}: \delta=0$ birim köke sahiptir

$H_{1}: \delta<0$ birim köke sahip değildir

Ho hipotezi durağan olmayan seriyi verirken alternatif hipotez serinin durağan olduğunu doğrular.

\subsubsection{Granger Nedensellik Testi}

Granger (1986), iki zaman serisi arasındaki ilişkinin tespitinde nedensellik testini geliştirmiştir. $\mathrm{Bu}$ testin amacı değişkenler arasındaki ilişkinin varlığını belirlemek, eğer ilişki varsa ilişkinin yönünü ve neden sonuç ilişkilerini belirlemektir. $\mathrm{Bu}$ testin uygulanabilmesi için serilerin durağan olması gerekmektedir. Granger nedensellik testi aşağıdaki iki denklemin tahminiyle gerçekleşmektedir (Gujarati, 2004).

$$
\begin{aligned}
& \Delta \mathrm{X}_{\mathrm{t}}={ }^{\mathrm{m}} \sum_{\mathrm{j}=1} \alpha_{\mathrm{j}} \Delta \mathrm{X}_{\mathrm{t}-\mathrm{j}}+{ }^{\mathrm{q}} \sum_{\mathrm{j}=1} \mathrm{~b}_{\mathrm{j}} \Delta \mathrm{Y}_{\mathrm{t}-\mathrm{j}}+\mathrm{u}_{\mathrm{t}} \\
& \Delta \mathrm{Y}_{\mathrm{t}}={ }^{\mathrm{r}} \sum_{\mathrm{j}=1} \mathrm{c}_{\mathrm{j}} \Delta \mathrm{Y}_{\mathrm{t}-\mathrm{i}}+{ }^{\mathrm{s}} \sum_{\mathrm{j}=1} \mathrm{~d}_{\mathrm{j}} \Delta \mathrm{X}_{\mathrm{t}-\mathrm{i}}+\mathrm{v}_{\mathrm{t}}
\end{aligned}
$$

bu denklemlerde $\alpha_{\mathrm{j}}, \mathrm{b}_{\mathrm{j}}, \mathrm{c}_{\mathrm{j}}$, $\mathrm{d}_{\mathrm{j}}$ gecikme katsayıları, $m, q, r$, sgecikme dönemleri $u, v$ hata terimleri, $\Delta$ ise fark alma operatörüdür. Tüm $b$ ve $d$ katsayılarının istatistiksel olarak sıfıra eşit olup olmadıkları, F-testi yardımıyla bulunarak aşağıdaki hipotezler sinanir. yoktur.

$$
H_{0}=b_{1}=b_{2}=b_{3}=\ldots=b_{q}=0 \quad \mathrm{Bu} \text { hipotez kabul edilirse Y'den X'e nedensellik }
$$

$H_{0}=\mathrm{d}_{1}=\mathrm{d}_{2}=\mathrm{d}_{3}=\ldots=\mathrm{d}_{\mathrm{s}}=0$ Bu hipotez kabul edilirse X'den Y'ye nedensellik yoktur.

\subsection{Veri Analizi}

Araştırmada veri analizi E-views 5.1 paket programı aracılığıyla yapılmıştır. Verilerin çözümlenmesinde birim kök testleri (ADF, PP)ve Granger Nedensellik testinden faydalanılmıştır.

\section{AMPİRIK BULGULAR}

Araştırmanın bu bölümünde ekonometrik analizler sonucunda E-views 5.1 paket programı kapsamında elde edilen bulgulara yer verilmiştir.

\subsection{Birim Kök Testi Sonuçları}

Araştırmanın bu bölümünde birim kök testlerine ilişkin sonuçlar her zaman serisi için ayrı ayrı olarak değerlendirilmiştir. 
Tablo 2. Araba Satışları Değişkeni Birim Kök Testi

\begin{tabular}{|c|c|c|c|c|}
\hline \multicolumn{5}{|c|}{ SATIS } \\
\hline & & Sabitsiz ve trendsiz & Sabitli & Sabitli ve trendli \\
\hline \multirow[t]{3}{*}{ ADF } & Düzey & $1,01(0)$ & $1,91(0)$ & $2,34(0)$ \\
\hline & 1.Fark & $2,74(0)^{*}$ & $3,23(0)$ & $3,41(0)$ \\
\hline & 2.Fark & & $5,06(0)^{*}$ & $4,77(0)^{*}$ \\
\hline \multirow[t]{3}{*}{$\mathbf{P P}$} & Düzey & $1,29(2)$ & $2,51(5)$ & $3,18(8)$ \\
\hline & 1.Fark & $2,74(0)^{*}$ & $3,45(3)^{*}$ & $3,48(2)$ \\
\hline & 2.Fark & & & $6,37(3)^{*}$ \\
\hline \multirow{2}{*}{\multicolumn{5}{|c|}{$\begin{array}{l}\text { * ADF ve PP testi;\%5 anlamlılıkta kritik değer sabitsiz ve trendsiz model için } 1,95 \text {, sabitli ve trendsiz } \\
\text { model için } 2,98 \text {, sabitli ve trendli model için 3,60'dır. } \\
\text { *Parantez içi değerler Schwarz ve Newey-West Bandwidth kriterlerine göre hesaplanan gecikme } \\
\text { değerleridir. } \\
\quad \text { Araba satışları değişkeni incelendiğinde, ADF ve PP testlerine göre araba } \\
\text { satışları 2.farkında durağan hale gelmektedir. }\end{array}$}} \\
\hline & & & & \\
\hline \multicolumn{5}{|c|}{ Tablo 3. DOAS Değişkeni Birim Kök Testi } \\
\hline \multicolumn{5}{|c|}{ DOAS } \\
\hline & & Sabitsiz ve trendsiz & Sabitli & Sabitli ve trendli \\
\hline \multirow[t]{3}{*}{ ADF } & Düzey & $0,69(0)$ & $1,00(0)$ & $1,74(1)$ \\
\hline & 1.Fark & $2,05(0)$ & $2,57(0)$ & $2,43(0)$ \\
\hline & 2.Fark & & $3,62(1)^{*}$ & $4,80(1)^{*}$ \\
\hline \multirow[t]{3}{*}{$\mathbf{P P}$} & Düzey & $0,66(1)$ & $0,99(1)$ & $0,64(5)$ \\
\hline & 1.Fark & $2,03(1)^{*}$ & $2,51(3)$ & $2,36(3)$ \\
\hline & 2.Fark & & $4,52(1)^{*}$ & $9,67(6)^{*}$ \\
\hline
\end{tabular}

* ADF ve PP testi;\%5 anlamlllıkta kritik değer sabitsiz ve trendsiz model için 1,95 , sabitli ve trendsiz model için 2,98, sabitli ve trendli model için 3,60'dır.

*Parantez içi değerler Schwarz ve Newey-West Bandwidth kriterlerine göre hesaplanan gecikme değerleridir.

DOAS değişkeni incelendiğinde, ADF ve PP testlerine göre hisse senedi fiyatları 2.farkında durağan hale gelmektedir.

\section{Tablo 4. FROTO Değişkeni Birim Kök Testi}

\begin{tabular}{|c|c|c|c|c|}
\hline & & \multicolumn{3}{|l|}{ FROTO } \\
\hline & & Sabitsiz ve trendsiz & Sabitli & Sabitli ve trendli \\
\hline \multirow[t]{2}{*}{ ADF } & Düzey & $3,90(1)^{*}$ & $1,97(1)$ & $1,43(1)$ \\
\hline & 1.Fark & & $3,41(0)^{*}$ & $4,95(0)$ \\
\hline \multirow[t]{2}{*}{$\mathbf{P P}$} & Düzey & $3,51(0)^{*}$ & $1,35(0)$ & $1,74(2)$ \\
\hline & 1.Fark & & $3,41(0) *$ & $9,64(7)^{*}$ \\
\hline
\end{tabular}

* ADF ve PP testi;\%5 anlamlllıkta kritik değer sabitsiz ve trendsiz model için 1,95 , sabitli ve trendsiz model için 2,98, sabitli ve trendli model için 3,60'dır.

*Parantez içi değerler Schwarz ve Newey-West Bandwidth kriterlerine göre hesaplanan gecikme değerleridir.

FROTO değişkeni incelendiğinde, ADF ve PP testlerine göre hisse senedi fiyatları 1.farkında durağan hale gelmektedir. 
Tablo 5. TOASA Değişkeni Birim Kök Testi

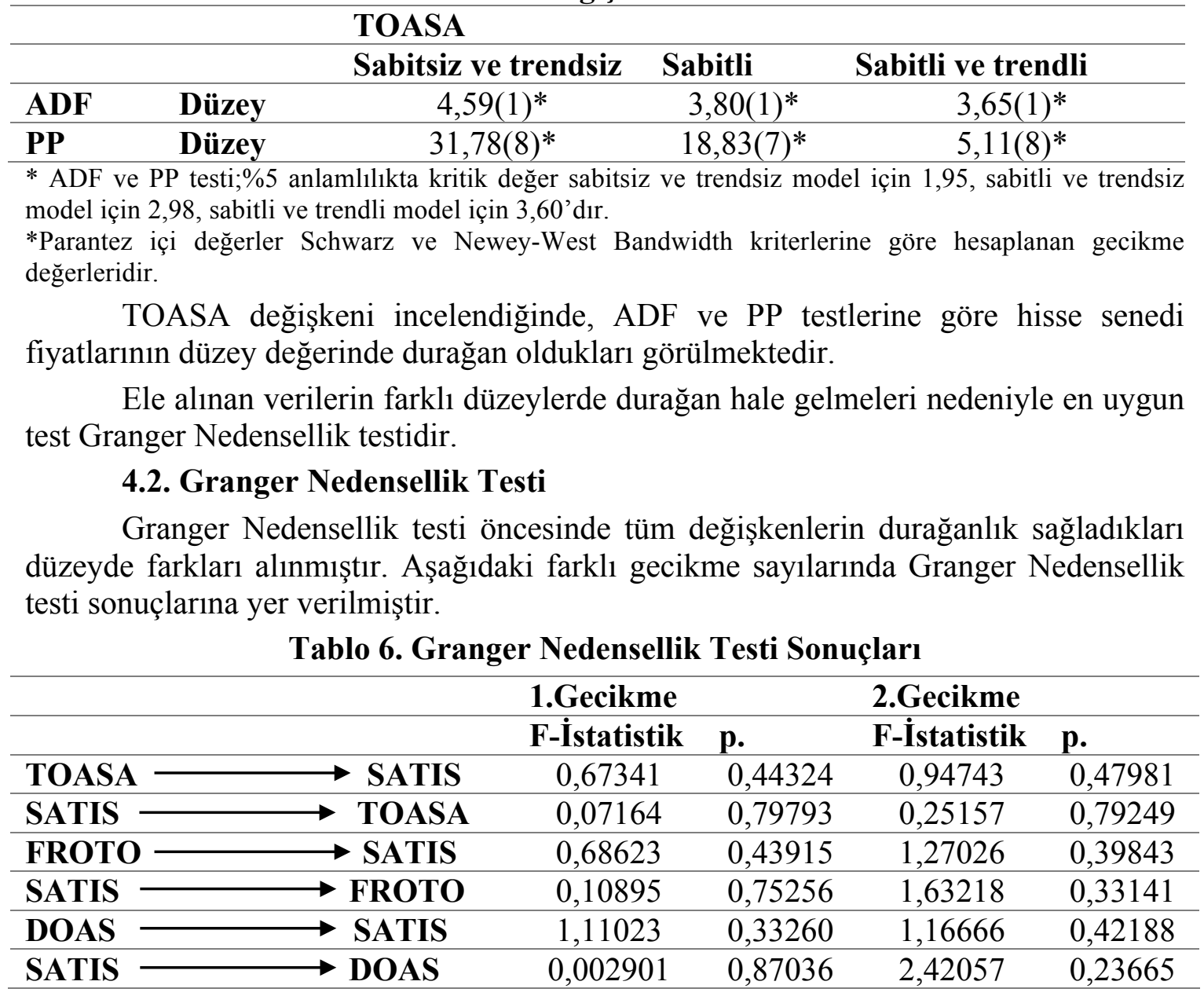

Granger Nedensellik testi sonuçlarına göre 1. ve 2. gecikme değerlerine göre hisse senedi fiyatları ile araba satış rakamları arasında istatistiksel olarak anlamlı ilişki rastlanmamıştır $(\mathrm{p}>0,05)$.

\section{SONUÇ}

Otomotiv sektörü, sürekli olarak büyüyen, ekonomilerin lokomotifi görevini üstlenen en önemli sektörlerden biri olarak görülmektedir. $\mathrm{Bu}$ araştırmada otomotiv sektörünün reel sektör verileri ile sermaye piyasası sektör verileri arasındaki ilişki tespit edilmeye çalışılmıştır. Reel Otomotiv sektörünü temsil etmesi amacıyla Türkiye'de yıllık olarak satılan binek otomobil sayıları veri olarak alınmıştır. Sermaye piyasasını temsil etmek amaciyla ise BİST'te işlem gören TOASA, DOAS ve FORTO hisse senedi fiyatları alınmıştır. Araştırma sonucunda reel sektör verisi ile hisse senetleri fiyatları arasında istatistiksel olarak anlamlı farklılık tespit edilememiştir. Bu durum literatürdeki çalışmalardan farklılık göstermektedir. Çünkü bu alanda sınırlı olan çalışmaların tümünde otomobil satışları ile otomobil firması hisse senedi getirileri arasında anlamlı ve pozitif yönde bir ilişki sözkonusu idi, dolayısıyla bu çalışma, literatürdeki çalışmalarla uyumlu değildir. Bu durum hisse senetlerinin reel sektöre göre hareket etmemesinden ve hisse senedi fiyatlarını etkileyen birçok faktörün mevcut olmasından kaynaklanıyor olabilir. Türkiye'de borsada işlem gören hisse senetlerinin reel sektör firmalarını tam olarak yansıtmadığını söylemek mümkündür. Sermaye piyasası kuralları ile reel sektör kuralları birbirinden farklıdır ve bu farklılık iki sektör arasında ilişkiyi ortadan kaldırmaktadır. 


\section{KAYNAKÇA}

Aksakal, H. (2016). "Japon Ve Türk Modernleşmelerinin Karşılaştırmalı Tarihi Üzerine Bir Değerlendirme Gerçekten “Japon Mucizesi” vs.“Türk Usûlü” Mü?”. Selçuk Üniversitesi Edebiyat Fakültesi Dergisi, (27), 83-108.

Aktaş, C., \& Akkurt, H. (2015). "ARCH Modelleri Ve Türkiye'ye Ait Otomobil Üretimi Verilerinin Farklı Varyanslığının İncelenmesi”. Dumlupınar Üniversitesi Sosyal Bilimler Dergisi, (16):87-106.

Çalışkan N. (2009). Türkiye'de Taşıt Kredilerinin Otomobil Satışlarına Etkisinin Ekonometrik Analizi, Yüksek Lisans Tezi, Marmara Üniversitesi, Sosyal Bilimler Enstitüsü, İşletme Anabilim Dalı, Finansal Piyasalar ve Yatırım Yönetimi Bilim Dalı, İstanbul.

Edwards, Charles. E., \& Stansell, Stanley, R. (1983). "New Car Sales Data and Automobile Company Stock Prices: A Study of the Causal Relationships". Business Economics, 18(3), 27-35.

Görener, A. G. Ö. (2008). "Türk Otomotiv Sektörünün Ülke Ekonomisine Katkilari ve Geleceğe Yönelik Sektörel Beklentiler". Journal of Yaşar University, 3(10), 1213-1232.

Gujarati, D. N. (2004). Basic Econometrics, The McGraw-Hill, New York.

Hoffer, George. E., \& Reilly, Robert.J. (1984). "Automobile Styling As A Shift Variable: An Investigation By Firm and Industry". Journal Applied Economics, 16(2), 291-298.

Ittner, Christopher. D., \& Larcker, David. F. (1997). "Product Development Cycle Time and Organizational Performance". Journal of Marketing Research, 34(1), 13-23.

İnançlı, S., \& Konak, A. (2014). "Türkiye'de ihracatın ithalata bağımlılığı: otomotiv sektörü”. Eskişehir Osmangazi Üniversitesi İktisadi ve İdari Bilimler Dergisi, $6(2), 343-362$.

Karabulut T. (2002). Türk Otomotiv Sanayii'nin Ekonomik Yapıs1 ve Otomobil Talep Analizi (1980-2000), Doktora Tezi, Selçuk Üniversitesi, Sosyal Bilimler Enstitüsü, İktisat Anabilim Dalı, İktisat Teorisi Bilim Dalı, Konya.

Kaymak M. (2009). 20. Yüzyılda Alternatif Enerji Kaynaklarının Gelişimi ve Buna Paralel Olarak Otomobil Tasarımına Etkileri, Yüksek Lisans Tezi, Anadolu Üniversitesi, Fen Bilimleri Enstitüsü, Endüstriyel Sanatlar Anabilim Dalı, Eskişehir.

Kleinschmidt, E.J., \& Cooper, R.G. (1991). "The Impact of Product Innovativeness on Performance". Journal of Product Innovation Management, 8(4), 240-251.

Laux, J. M. (1992). The European automobile industry (p. 13). New York: Twayne.

OICA, http://www.oica.net/category/production-statistics/

OSD (2017). Otomotiv Sanayii Genel ve İstatistik Bülteni http://www.osd.org.tr/sites/1/upload/files/Yillik_2017-2224.pdf

Pauwels, Koen., Risso Jorge Silva., Srinivasan, Shuba,. \& Hanssens, Dominique. M. (2004). "New Products, Sales Promotions and Firm Value: The Case of the Automobile Industry". Journal of Marketing, 68(4), 142-156.

Sturgeon, T. J., \& Van Biesebroeck, J. (2011). "Global value chains in the automotive industry: an enhanced role for developing countries?". International Journal of Technological Learning, Innovation and Development, 4(1-3), 181-205.

Sturgeon, T., \& Van Biesebroeck, J. (2010). "Effects of the crisis on the automotive industry in developing countries: a global value chain perspective".Policy Research Working Paper 5330. 
Verstrepen, S., Deschoolmeester, D., \& Van den Berg, R. J. (1999). "Servitization in the automotive sector: creating value and competitive advantage through service after sales". In Global production management (pp. 538-545). Springer, Boston, MA.

Yurdakul, M., \& İç, Y. T. (2003). "Türk Otomotiv Firmalarının Performans Ölçümü ve Analizine Yönelik Topsıs Yöntemini Kullanan Bir Örnek Çalışma”. Gazi Üniversitesi Mühendislik-Mimarlık Fakültesi Dergisi, 18(1).

Zapata, C., \& Nieuwenhuis, P. (2010). "Exploring innovation in the automotive industry: new technologies for cleaner cars". Journal of Cleaner Production, 18(1), 14-20. 


\section{The Analysis Of The Relationship Between The Automobile Sales And Automotive Industry Stock Prices By Granger Causality Test: Istanbul Stock Exchange Case}

\author{
Zafer ŞAHIN \\ Dumlupınar University \\ Institute of Social Sciences Graduate \\ Student, Kütahya, Turkey \\ orcid.org/0000-0002-2765-3138 \\ zafer.sahin111@gmail.com
}

\author{
Cumhur ŞAHIN \\ Bilecik Şeyh Edebali University \\ Bozüyük Vocational School \\ Bozüyük, Bilecik, Turkey \\ orcid.org/0000-0002-8790-5851 \\ cumhur.sahin@bilecik.edu.tr
}

\section{Extensive Summary}

\section{Introduction}

In general, automotive sector is a sector working for the production of road vehicles and the production of parts required for the production of vehicles. The automotive sector is seen as one of the most important sectors for all countries of the world. It is also at a leading position especially in the industrialized countries. The fact that the automotive industry is a leading sector is due to the fact that it is in a relation with many other sectors. The automotive sector is closely related to many sectors such as petro-chemistry, iron, steel and rubber sectors. The automotive sector is the buyer in these sectors. Therefore, the size of the automotive sector plays an important role in the development of these sectors. When the automotive sector is in a seller position, it is closely related to some other sectors such as tourism, agriculture, construction and transportation. Therefore, changes that might occur in the automotive sector may affect other sectors as well.

As in all sectors, the automotive sector has an important role in the capital market as well as being effective in the real sector. On the other hand, it is an obvious fact that the real sector and the capital sector are not totally related. In the present research, a comparison will be made between real market data and capital market data for the automotive sector. Besides, it will be investigated whether there is a relationship between new automobile sales and share earnings in automotive companies. In literature, it is considerable that there have been a number of studies in the automotive sector that address the relationship between stock prices and macroeconomic variables such as inflation, interest rates, exchange rates and especially crude oil prices, whereas there has been a limited number of studies carried out on the relationship between automobile sales and the automobile sector share prices. Moreover, all of the existing studies have been based on studies abroad, and it was seen that there has been no study related to this topic in our country. This is the reason why this research topic was chosen. Therefore, it is thought that the current research will contribute to fulfill a need in the literature.

\section{Data and Method}

In the research, it was planned to carry out a research on the demand of noncommercial customers and the related stock values in the selection of data for the 
automotive sector. In this context, the relationship between selected stock prices and total values for car sales in Turkey was examined.

The data set used in the research is as follows:

- DOAS: The average annual stock price in Doğuş Automotive (2008-2017)

- TOASA: The average annual stock price in Tofaş (2008-2017)

- FROTO: The average annual stock price in Ford Otosan (2008-2017)

- SATIS: The total number of new cars sold in Turkey (2008-2017)

Share prices were taken from BIST official website, while the total number of new cars sold in Turkey was taken from the OICA website. While including the data in the analysis, their logarithms were taken.

After checking whether the time series were static or not, it was decided that the most appropriate test was the Granger Causality test, since the data received were to be static at different levels.

\section{Findings and Conclusion}

Before the Granger causality test, differences were taken at the level where all variables were static. According to the 1st and 2nd delay values in Granger causality test results, no statistically significant correlation was found between stock prices and car sales figures. As a result of the research, no statistically significant difference was found out between real sector data and share prices. This is different from the previous studies in the literature because in this limited area of work, there was a significant and positive correlation between automobile sales and share earnings in automobile company. Therefore, this research is incompatible with the literature. This may be due to the fact that shares do not act according to the real sector and there are many factors affecting share prices. It can be said that the figures for stock exchange securities do not totally reflect the values for the real sector companies in Turkey. The capital market rules and the real sector rules are different from each other. This difference eliminates the relationship between the two sectors. 